This item was submitted to Loughborough's Research Repository by the author.

Items in Figshare are protected by copyright, with all rights reserved, unless otherwise indicated.

\title{
Novel sea buckthorn biocarbon SBC@beta-FeOOH composites: Efficient removal of doxycycline in aqueous solution in a fixed-bed through synergistic adsorption and heterogeneous Fenton-like reaction
}

\section{PLEASE CITE THE PUBLISHED VERSION}

http://dx.doi.org/10.1016/j.cej.2015.09.012

\section{PUBLISHER}

(C) Elsevier

\section{VERSION}

AM (Accepted Manuscript)

\section{PUBLISHER STATEMENT}

This work is made available according to the conditions of the Creative Commons Attribution-NonCommercialNoDerivatives 4.0 International (CC BY-NC-ND 4.0) licence. Full details of this licence are available at: https://creativecommons.org/licenses/by-nc-nd/4.0/

\section{LICENCE}

CC BY-NC-ND 4.0

\section{REPOSITORY RECORD}

Zhang, Xia, Bo Bai, Gianluca Li-Puma, Honglun Wang, and Yourui Suo. 2016. "Novel Sea Buckthorn Biocarbon Sbc@beta-feooh Composites: Efficient Removal of Doxycycline in Aqueous Solution in a Fixed-bed Through Synergistic Adsorption and Heterogeneous Fenton-like Reaction". figshare.

https://hdl.handle.net/2134/20372. 
$6{ }^{a}$ College of Environmental Science and Engineering, Chang'an University, Xi'an, 710054,

$7 \quad$ P.R. China; baibo@chd.edu.cn

\section{Heterogeneous Fenton-like Reaction}

\author{
Xia Zhang ${ }^{\mathrm{a}}$, Bo $\underline{B a i}^{*}{ }^{\mathrm{b}}$, Gianluca Li Puma ${ }^{\mathrm{c}}$, Honglun Wang ${ }^{\mathrm{b}}$, Yourui Suo ${ }^{\mathrm{b}}$
}

${ }^{b}$ Northwest Plateau Institute of Biology, Chinese Academy of Sciences, Xining, 810001, People’s Republic of China;

${ }^{c}$ Environmental Nanocatalysis \& Photoreaction Engineering, Department of Chemical Engineering, Loughborough University, Loughborough, LE11 3TU, United Kingdom.

* Corresponding author: Tel: +86 298233 9052; Fax: +86 298233 9961; Email:

14 
Abstract: Akaganeite ( $\beta$-FeOOH) nanoparticles were successfully anchored on the surface of porous sea buckthorn biocarbon (SBC) via a simple low-temperature hydrothermal process without use surfactants or external forces. The SBC@ $\beta$-FeOOH composite was characterized by X-ray diffraction (XRD), scanning electron microscopy (SEM), and energy dispersive spectrometry (EDS). On the basis of characterization methods, a possible mechanism of formation of the SBC@ $\beta-\mathrm{FeOOH}$ composite was discussed. The SBC@ $\beta-\mathrm{FeOOH}$ composite was used in fixed-bed columns for the effective removal of doxycycline (DC) from an aqueous solution, by the synergistic effect of adsorption and Fenton-like oxidation reaction. The effects of inlet DC concentration (22-32 mg/L) feed flow rate (1-3 mL/min) SBC@ $\beta-F e O O H$ bed depth $(0.7-1.5 \mathrm{~cm})$ and $\mathrm{pH}(2-11)$ on the adsorption breakthrough profiles were investigated. The adsorption process was controlled by the ionic speciation of the adsorbate DC and the available binding sites of SBC@ $\beta$-FeOOH. It was simulated by the Thomas and Yoon-Nelson models at different conditions. The bed of SBC@ $\beta-\mathrm{FeOOH}$ saturated with DC was readily regenerated, in situ, by a heterogeneous Fenton-like oxidation reaction. The synergistic effect resulting from the biosorption nature of SBC and the catalytic oxidation properties of the supported $\beta$-FeOOH nanoparticles results in a new promising composite material for water treatment and purification.

Key Words: SBC@ $\beta$-FeOOH; DC; Fixed-bed; Removal; Regeneration

\section{Introduction}

Adsorption using activated carbons is a widely used method to remove pollutants from water and wastewater [1-4]. However, the use of commercial activated carbons for water treatment can 
be limited due to their relative high cost, especially in developing countries. In an effort to reduce the cost of the carbon sorbent material, the production of activated biocarbons from agricultural waste residues has attracted significant attention, also led by a sustainable utilization of natural carbon resources and the respect to the environment. For example, classical agricultural waste including rice husk [5], cocoa shell [6], peanut hull [7], trapa natans husk [8], grape stalk [9], cotton stalk [10] etc., have been extensively utilized for the preparation of activated biocarbon with a high adsorption capacity, substantial mechanical strength and low ash content [11]. Sea buckthorn is a thorny and branched deciduous shrub, 3-15 feet high, widely distributed in many countries including China, India, Pakistan, Nepal, Myanmar, Finland, Russia, Romania, Germany, Britain, and many other high altitude areas [12]. Nevertheless, sea buckthorn branches, as the by-product during the picking process of the fruit, have already given rise to environmental problems because of the chronic and casual disposal or incineration, which in turn may cause further water or air pollution. As a typical carbon-rich, cost-free and abundant agricultural solid waste, sea buckthorn branches offer a good natural source for the sustainable production of an effective activated biocarbon.

The treatment of contaminated water by heterogeneous Fenton oxidation with traditional slurry suspensions of iron oxide can be an expensive process since often large volumes of reagents $\left(\mathrm{H}_{2} \mathrm{O}_{2}\right)$ and catalyst $\left(\mathrm{Fe}^{2+}\right)$ are needed, the water matrix usually consume inefficiently $\bullet \mathrm{OH}$ radicals and in consequence, longer contact times are often required [13,14]. In contrast, the efficiency of the heterogeneous Fenton process for the treatment of wastewater can be increased significantly by applying an enrichment or pre-concentration sorption method prior to the oxidation of the contaminants by the Fenton process on the immobilized iron oxide [15,16]. For example, in our previous study the embedding of $\mathrm{Fe}_{3} \mathrm{O}_{4}$ nanoparticles onto the surface of yeast integrated the 
biosorption features of yeast cells with the magnetic and Fenton catalytic properties of $\mathrm{Fe}_{3} \mathrm{O}_{4}$ nanoparticles, which was highly effective for the removal and oxidation of the cationic dye methylene blue in water and wastewater [17]. The enhanced performance of this composite catalyst can be attributed to the consecutive and synergistic effect of yeast biosorption and $\mathrm{Fe}_{3} \mathrm{O}_{4}$ nanoparticles heterogeneous Fenton oxidation/regeneration cycles.

Akaganeite, $\beta-\mathrm{FeOOH}$, has been reported as a promising material for Fenton-like reactions in heterogeneous systems, due to its large tunnel-type structure with iron atoms strongly bonded to the framework [18-20]. Miyata et al. [21] reported that $\beta$-FeOOH was the most active among a range of iron oxides and hydroxides $\left(\alpha-\mathrm{FeOOH}, \beta-\mathrm{FeOOH}, \mathrm{Fe}_{3} \mathrm{O}_{4}, \alpha-\mathrm{Fe}_{2} \mathrm{O}_{3}\right.$ and $\left.\gamma-\mathrm{Fe}_{2} \mathrm{O}_{3}\right)$ for the reduction of 4-nitrotoluene. Zhang et al. [22] developed $\mathrm{TiO}_{2} / \beta-\mathrm{FeOOH}$ composite catalysts, which exhibited excellent catalytic activity for the reduction of $\mathrm{Cr}(\mathrm{VI})$.

Inspired by this background, in this study we have assembled $\beta$-FeOOH nanoparticles onto SBC activated biocarbons scaffolds through a simple hydrothermal process. Based on the XRD, SEM, and EDS characterization methods, a possible formation mechanism of the SBC@ $\beta-\mathrm{FeOOH}$ composite was proposed. The adsorption and catalytic properties of the SBC@ $\beta-\mathrm{FeOOH}$ were investigated for the removal of doxycycline (DC), a common antibiotics compound used in human therapy and the livestock industry [23-27], over a continuous, fixed-bed column system operated in a cyclical manner of adsorption and regeneration. The breakthrough curves for the adsorption of DC in the fixed-bed column were analyzed using mathematical models. The regeneration of the saturated SBC@ $\beta$-FeOOH composite sorbent was carried out by triggering the Fenton oxidation reaction over the immobilized iron $(\beta-\mathrm{FeOOH})$ by flowing an aqueous $\mathrm{H}_{2} \mathrm{O}_{2}$ solution. The robustness of the materials over multiple loading and regeneration cycles makes it feasible for practical environmental applications. 


\section{Materials and methods}

\subsection{Materials}

The sea buckthorn branches used in this work were collected from Qinghai Province. Ferric chloride hexahydrate $\left(\mathrm{FeCl}_{3} \cdot 6 \mathrm{H}_{2} \mathrm{O}\right)$, urea $\left(\mathrm{CON}_{2} \mathrm{H}_{4}\right)$, zinc chloride $\left(\mathrm{ZnCl}_{2}\right)$ and DC $\left(\mathrm{C}_{22} \mathrm{H}_{24} \mathrm{~N}_{2} \mathrm{O}_{8}\right)$ were provided by Xi'an Chemical Agent Corp. All chemicals used in this work were of analytical grade and used without further purification. Distilled water was used through all the experiments.

\subsection{Fabrication of SBC@ $\beta$-FeOOH}

Sea buckthorn branches were impregnated with the activating agent $\mathrm{ZnCl}_{2}$ in a $1 / 1(\mathrm{w} / \mathrm{w})$ (waste/ $\mathrm{ZnCl}_{2}$ ) ratio, for $24 \mathrm{~h}$ at room temperature. The material was then pyrolyzed in a tubular furnace at the temperature of $773 \mathrm{~K}$ for $1 \mathrm{~h}$ under $\mathrm{N}_{2}$ atmosphere. The carbonized sample (SBC) was further washed with distilled water three times.

The SBC@ $\beta$-FeOOH was prepared by a hydrothermal reaction process. In detail, $0.05 \mathrm{M}$ $\mathrm{FeCl}_{3} \cdot 6 \mathrm{H}_{2} \mathrm{O}$ and $0.2 \mathrm{M}$ urea were firstly dissolved in distilled water at room temperature and under vigorous stirring to form a saffron yellow solution. Then, SBC was added to the saffron yellow solution and the color of the mixed solution changed to black. The mixture was transferred to a Teflon-lined stainless steel autoclave of $50 \mathrm{~mL}$ capacity and distilled water was added up to $80 \%$ of the total volume of the vessel. The vessel was sealed and maintained at $353 \mathrm{~K}$ for $6 \mathrm{~h}$. The autoclave was then allowed to cool down to room temperature under ambient conditions. The resulting products were filtered, washed with distilled water, and finally dried under vacuum at $333 \mathrm{~K}$ for $6 \mathrm{~h}$. 


\subsection{Characterizations of $\mathrm{SBC} @ \beta$-FeOOH}

With the purpose of measuring the composition and phase purity of the samples, X-ray diffraction (XRD) were carried out on a Rigaku D/MAX-3C diffractometer operated at a voltage of $40 \mathrm{kV}$ and a current of $20 \mathrm{~mA}$ at a 0.028 scan rate with $\mathrm{Cu}$ Ka radiation. Scanning electron microscopy (SEM) images were taken on a Tescan VEGA II LMH to determine the morphology of the SBC and SBC@ $\beta-\mathrm{FeOOH}$ materials. The elemental distribution of iron, carbon, and oxygen in the SBC@ $\beta$-FeOOH was evaluated using a multipoint energy-dispersive X-ray spectrometer (EDS; equipped with Hitachi S-2700 scanning electron microscope).

\subsection{Adsorption tests}

In order to investigate the synergistic effect of adsorption and the subsequent heterogeneous Fenton reaction, a fixed-bed column made of glass tube with an internal diameter of $0.6 \mathrm{~cm}$ and a length of $15 \mathrm{~cm}$ was packed with $\mathrm{SBC} @ \beta$-FeOOH and was operated in an up-flow mode. The effect of the influent DC concentration (22, 27 and $32 \mathrm{mg} / \mathrm{L}$ ), flow rate (1, 2, and $3 \mathrm{~mL} / \mathrm{min})$, bed depth $(0.7,1.1$ and $1.5 \mathrm{~cm})$ and $\mathrm{pH}(2,4,6,9,11)$ on the column performance were investigated. Effluent samples from the column were collected at defined time intervals and analyzed by a Jenway $6405 \mathrm{UV}$-vis spectrophotometer at $351 \mathrm{~nm}$.

The dynamic response and operation of the sorption column was evaluated by the analysis of the DC adsorption breakthrough profiles determined as the ratio $C_{\mathrm{t}} / C_{0}$ vs $t(\min )$, where $C_{0}$ is the influent concentration, $C_{\mathrm{t}}$ is the effluent concentration, and $t$ is the elapsed time. $Q(\mathrm{~mL} / \mathrm{min})$ is the influent flow rate and $t_{\text {total }}(\mathrm{min})$ is the total flow time.

The volume effluent $V_{\mathrm{Eff}}(\mathrm{mL})$ processed was determined as: 
The total mass of DC adsorbed, $q_{\text {total }}(\mathrm{mg})$, was estimated by the area described under the

breakthrough curve:

$$
q_{\text {total }}=\frac{Q}{1000} \int_{t=0}^{t=t_{\text {total }}}\left(C_{0}-C_{\mathrm{t}}\right) d t
$$

$\left(q_{\text {total }}\right)$ per gram of adsorbent $m$ (g) when steady state conditions in the column were reached.

$$
q_{\mathrm{e}}=\frac{q_{\text {total }}}{m}
$$

The total amount of DC fed to column $m_{\text {total }}$ (mg) was calculated from Eq.(4):

$$
m_{\text {total }}=\frac{C_{0} \cdot Q \cdot t_{\text {total }}}{1000}
$$
volume and the flow rate:

$$
\operatorname{EBCT}(\min )=\frac{\text { bed volume }(\mathrm{mL})}{Q(\mathrm{~mL} / \mathrm{min})}
$$

\subsection{Heterogeneous Fenton oxidation regeneration}

The regeneration of the saturated sorbent in the bed was carried out by injecting an aqueous solution of $\mathrm{H}_{2} \mathrm{O}_{2}$ at a flow rate of $1 \mathrm{~mL} / \mathrm{min}$ for $2 \mathrm{~h}$, which triggered a Fenton-like oxidation reaction and the oxidation of the sorbed contaminants. The bed was then washed with distilled above. 


\section{Results and discussion}

\subsection{Characterization of SBC@ $\beta$-FeOOH and formation mechanism}

Fig. 1

The XRD patterns of the primitive SBC powder (trace a), the parallel $\beta$-FeOOH nanoparticles (trace b) and the $\mathrm{SBC} @ \beta-\mathrm{FeOOH}$ samples (trace c) are presented in Fig. 1, respectively. The broad diffraction peak around $2 \theta=20^{\circ}$ (trace a) indicates that the primitive SBC powder was of amorphous structure. The same shape was well established in other amorphous substance such as yeast-based activated biocarbon or commercially available activated carbon [28, 29]. The XRD pattern of the parallel $\beta$-FeOOH nanoparticles (trace b), matched the diffraction of tetragonal akaganeite (JCPDS card No. 34-1266) with cell constants of $\mathrm{a}=\mathrm{b}=10.535 \AA$ and $\mathrm{c}=$ 3.030 A. Comparatively, the peaks of the as-prepared SBC@ $\beta-\mathrm{FeOOH}$ species (trace c) were in agreement with the theoretical data of the tetragonal $\beta$-FeOOH phase. Since no further impurities peaks were detected, the successful loading of $\beta$-FeOOH on the SBC@ $\beta-\mathrm{FeOOH}$ composites was confirmed.

Fig. 2

The formation of the $\beta$-FeOOH nanoparticles on the structure of SBC@ $\beta$-FeOOH composites was further investigated by SEM analysis. Fig. 2a displays the morphology of the naked SBC powder, which has irregular shape with a large amount of pores on the surface. At higher magnification (Fig. 2b), the SBC abundant cavities with diverse diameters pervaded homogeneously on the surface of SBC, which contributed to the relatively large specific surface area of the SBC@ $\beta$-FeOOH composites. Furthermore, the inset image in the bottom right corner of Fig. $2 \mathrm{~b}$ demonstrated the longitudinal cross-section of the pores exhibiting a distinct tubular 
shape. The loading of many $\beta$-FeOOH fine particles onto the SBC scaffold (Fig. 2c) led to a rough topographical surface of the SBC@ $\beta$-FeOOH composite. The surface of the SBC was covered by small $\beta$-FeOOH nanoparticles, however, the porous structure of the parent SBC was maintained, which should favour the adsorption of contaminants. The occurrence of choked phenomenon for a few pore channels, in comparison with the original SBC substrate, provided assertive evidence that the $\beta-\mathrm{FeOOH}$ nanoparticles were anchored onto the surface of the SBC scaffold. Further, the absence of scattering particles around the composite material implied a strong adhesion between the SBC scaffold and the $\beta$-FeOOH nanoparticles. The higher magnification image in Fig. $2 \mathrm{~d}$ shows $\beta$-FeOOH nanoparticle with an ellipsoidal morphology and smooth surface, resembling a 1D nanorods, 70-120 nm in width and 300-400 nm in length.

\section{Fig. 3}

The elemental composition of the composite was investigated by two-dimensional X-ray mapping of selected SBC@ $\beta$-FeOOH zones (Fig. 3a). EDS analysis of SBC@ $\beta$-FeOOH (the inset in the bottom left corner of Fig. 3a) showed that $\mathrm{C}$, O, and Fe were the main elemental constituents, confirming the purity of the composite. The clear $\mathrm{C}, \mathrm{O}$ and Fe elemental mapping images of SBC@ $\beta$-FeOOH (Fig. 3b-d), indicated the homogeneous dispersions of C, O, and Fe on the surface of SBC substrate. More importantly, the elaborative observation of Fig. 3d confirmed that $\beta$-FeOOH nanoparticles were almost uniformly deposited on the SBC surface.

On the basis of XRD, SEM and EDS, a possible formation mechanism of $\beta$-FeOOH nanocrystals on the SBC substrate was proposed. The mechanism includes attachment, nucleation, growth and surface-regulation. Initially, minute $\beta-\mathrm{FeOOH}$ nanocrystals, assembled on the SBC, are gradually produced with an attachment process. The SBC possesses rough surfaces rich in hydroxyl group, and the bonding property of these functional groups on the ferric ions favors the 
nucleation [30] of $\beta-\mathrm{FeOOH}$ on the SBC scaffold. The nucleation of nanocrystals is facilitated and energetically favoured, since the interfacial energy between the SBC and the $\beta$-FeOOH nanocrystal is smaller than the interfacial energy between the solution and the crystal. The granules formed at the early stage act as the cores for the further growth of $\beta$-FeOOH crystallites. With the adsorption to the ferric ions in $\beta$-FeOOH crystal nucleus, the epitaxial crystal growth takes place, at a suitable nucleating velocity, along the most favourable direction of crystallization from the nuclei, following a structure identified by a stack of $\mathrm{O}_{3}$ and $\mathrm{Fe}$ layers: $-\mathrm{Fe}-\mathrm{Fe}-\mathrm{O}_{3}-\mathrm{Fe}-\mathrm{Fe}-\mathrm{O}_{3}-[31]$. The $\mathrm{N}-\mathrm{C}=\mathrm{O}$ groups of urea easily attach to the surface of the crystal faces gradually reducing the rate of growth of the crystal at the given crystallographic orientation [32], eventually blocking the further growth of these planes at later reaction times. In parallel, the subsequent nucleation and precipitation of $\beta-\mathrm{FeOOH}$ at an appropriately controlled rate and the anisotropic growth of the $\beta$ - $\mathrm{FeOOH}$ nanocrystals, continues. This results in the growth of ellipsoid nanostructures. Finally, well-defined SBC@ $\beta-\mathrm{FeOOH}$ composite materials are obtained with the rough surface assembled by $\beta-\mathrm{FeOOH}$ nanorods. The proposed mechanism was more explained by scheme reactions as follows:

\subsection{Effects of operating conditions on DC adsorption in a fixed bed column}

The performance of the SBC@ $\beta$-FeOOH composite was evaluated in a fixed-bed column process operated for the sorption of DC from aqueous solutions. The use of a fixed-bed column process [33-36] allows more effective utilization of the absorbent capacity of the sorbent and 
results in an effluent with higher quality [37]. In addition, in comparison with the batch method, the use of a fixed-bed column allows more effective cycles of adsorption/regeneration and reuse of the sorbent, and ultimately the scale-up of fixed-bed columns from the laboratory to pilot and industrial scale.

\subsubsection{Effect of initial DC concentration, bed depths and flow rate}

Fig. 4

The breakthrough profiles in Fig. 4a show that the breakthrough time decreased from 80 to $48 \mathrm{~min}$ when the concentration of DC of the influent varied from 22 to $32 \mathrm{mg} / \mathrm{L}$ in a bed of $1.1 \mathrm{~cm}$ in depth, operated at a flow rate of $1 \mathrm{~mL} / \mathrm{min}$ and $\mathrm{pH}$ 6. These results are summarized in Table 1.

The breakthrough curves were sharper at higher DC concentration, which suggested a relatively smaller depth of the mass-transfer zone and that intraparticle diffusion of the DC controlled the adsorption process. Equal observations have been reported for the biosorption of $\mathrm{Cr}$ (III) by olive stones [38] and in the removal of methylene blue by rice husk [39]. In addition, since the total amount of DC adsorbed decreased with increasing concentrations of DC in the influent, the diffusion process was concentration dependent.

The rate of accumulation of DC in the fixed-bed column is a function of the total mass of sorbent in the column. Fig. 4b show that the breakthrough time increased as the SBC@ $\beta-\mathrm{FeOOH}$ bed depth varied from 0.7 to $1.5 \mathrm{~cm}$, at a flow rate of $1.0 \mathrm{~mL} / \mathrm{min}$, an influent DC concentration of $27 \mathrm{mg} / \mathrm{L}$ and $\mathrm{pH}$ 6. The EBCT increased from 0.198 to $0.424 \mathrm{~min}$ as the bed depth was increased, which implies that the DC molecules could diffuse more effectively into the pore structure of the SBC@ $\beta-F e O O H$ with increased bed-depths. In this case, the mass-transfer zone formed moves further down the bed when bed depth increases, allowing a more effective contact between DC the 
SBC@ $\beta-\mathrm{FeOOH}$ in the column. On the other hand, the slope of the breakthrough curve reduced as the bed depth increased, which implies a broadening of the mass transfer zone. Obviously, the highest adsorption capacity occurred at the highest bed depth, since the total surface area of the adsorbent increased [40-42].

The breakthrough curves of DC at various flow rates from 1.0 to $3.0 \mathrm{~mL} / \mathrm{min}$ with a bed depth of $1.1 \mathrm{~cm}, \mathrm{pH} 6$ and an initial DC concentration of $27 \mathrm{mg} / \mathrm{L}$ are shown in Fig. 4c. The breakthrough time decreased significantly with an increase in the flow rate, however, as the flow rate increased, much sharper breakthrough curves for DC adsorption onto SBC@ $\beta-\mathrm{FeOOH}$ were observed. This results from a decrease in the contact time, which diminished the interaction of the DC solution with the SBC@ $\beta$-FeOOH. In other words, at a lower flow rate DC had longer time to diffuse into the pores of the SBC@ $\beta-\mathrm{FeOOH}$ and this resulted in a higher removal of DC in the column. Hence, breakthrough occurred later, resulting in higher bed adsorption capacity. Additionally, increasing the flow rate increases the rate of external mass transfer film thickness and resistance decreased by, leading to a higher overall mass transfer coefficient and adsorbate fluxes [43].

\subsubsection{Effect of $p H$}

The $\mathrm{pH}$ is an important factor that affects the sorption capacity of the sorbent. The $\mathrm{pH}$ has a significant effect of on the prevalent adsorption mechanisms and reflects the nature of the physico-chemical interaction of the compounds in solution and the binding sites of the sorbent [44]. Thus the $\mathrm{pH}$ of DC solution fed to the bed was fixed at 2.0, 4.0, 6.0, 9.0, and 11.0, while the influent DC concentration, flow rate and bed depth were kept constant at $27 \mathrm{mg} / \mathrm{L}, 1 \mathrm{~mL} / \mathrm{min}$, and $1.1 \mathrm{~cm}$, respectively. The results presented in Figure 4(d) and Table 1shows that an increase in $\mathrm{pH}$ 
of the feed solution decreases the volume of water treated until breakthrough of the bed occurred.

In addition, as $\mathrm{pH}$ decreased, the breakthrough curves shifted to longer times removing more DC molecules. DC is an amphoteric molecule with multiple ionizable functional groups such as amino, phenol and alcohol at various $\mathrm{pH}$ values and has three $\mathrm{pK}_{\mathrm{a}}$ values (3.5, 7.7 and 9.5), thus its predominant species are cation $\left(\mathrm{DC}^{+}\right)$(below $\mathrm{pH} 3.5$ ), due to the protonation of dimethyl-ammonium group, zwitterion ( $\mathrm{DC}^{0}$ ) (between $\mathrm{pH} 3.4$ and 7.7), when the proton of phenolic diketone moiety is lost, and anion ( $\mathrm{DC}^{-}$and $\mathrm{DC}^{2-}$, respectively, above $\mathrm{pH} 7.7$ and 9.5), resulting from the loss of protons from the phenolic diketone moiety and tri-carbonyl system. For SBC@ß-FeOOH, a low pH increased protonation, and this contributed to the diffusion of DC into the pores and generated a great deal of active sites on the surface of adsorbents [45]. Thus the increased adsorption capacity of DC at acidic condition results from the cationic character of DC [46]. $\mathrm{DC}^{0}$ becomes predominant between $\mathrm{pH} 4$ and 6, which decreases the electrostatic interatction with the sorbent and, therefore, the adsorption of DC through the surface of the SBC@ $\beta-\mathrm{FeOOH}$ resulted in a shorter breakthrough time. When the $\mathrm{pH}$ is above $9, \mathrm{DC}^{0}$ begins to transform into $\mathrm{DC}^{-}$and $\mathrm{DC}^{2-}$. The decreased adsorption of DC results from the ionization of the surface oxygenated groups of the SBC at more alkaline $\mathrm{pH}$, which results in higher negative surface charge density. Thus repulsive electrostatic forces can occur between the adsorbent and the DC amounts under alkaline conditions may result from the weak interaction of cation- $\pi$ bonding and $\pi-\pi$ stacking with SBC@ $\beta$-FeOOH during the DC adsorption process [48]. 
The design and scale-up of fixed-bed adsorption columns requires the evaluation of the breakthrough curves of the effluent. Among many mathematical models that have been proposed for the design of fixed-bed adsorption systems, in this study we used the Thomas [49] and Yoon-Nelson [50] models, which are among the most widely and common methods.

\subsubsection{Thomas model}

The Thomas model estimates the dependence of solute concentration with time, in a fixed bed column, when internal and external mass transfer limitations are insignificant and in the absence of axial dispersion. The model has the following form:

$$
\ln \left(\frac{C_{0}}{C_{\mathrm{t}}}-1\right)=\frac{k_{\mathrm{T}} q_{0} m}{Q}-k_{\mathrm{T}} C_{0} t
$$

where $k_{\mathrm{T}}$ is the Thomas rate constant ( $\left.\mathrm{mL} / \mathrm{min} \mathrm{mg}\right), m$ is the mass of adsorbent $(\mathrm{g}), q_{0}$ is the the adsorption of DC very well. Moreover, the values of $k_{\mathrm{T}}$ decreased as the initial influent DC 
on the adsorption process. The highest $k_{\mathrm{T}}$ value at the lowest $C_{0}$ indicated that the adsorption of the DC was kinetically favorable at lower solute concentrations. The decrease of $q_{0}$ noted results from a decrease in the driving force for adsorption between the concentration of DC in the bulk and on the sorbent. Again, as the bed depth increased, the rate constant $\left(k_{\mathrm{T}}\right)$ decreased while the equilibrium uptake capacity $\left(q_{0}\right)$ significantly increased. The values of $k_{\mathrm{T}}\left(\mathrm{mL} / \mathrm{min} \bullet \mathrm{mg}^{-1}\right)$ were 2.782, 6.267, and 12.467, respectively, with increasing flow rate of effluent while the values of $q_{0}$ decreased from 4.593 to 4.181 . The increase of $k_{\mathrm{T}}$ value indicates the decrease of the mass-transport resistance and axial dispersion. And the decrease of $q_{0}$ is obvious as the adsorption capacity is directly proportional to the contact time. Thus, lower initial concentration, lower flow rate, and higher bed heights increase the rate of adsorption of DC in the SBC@ $\beta$-FeOOH column.

\subsubsection{Yoon-Nelson model} the sorbent decreases as the fraction of solute being adsorbed decreases and as breakthrough is approached. The equation regarding to a single component system is expressed as:

$$
\ln \frac{C_{\mathrm{t}}}{C_{0}-C_{\mathrm{t}}}=k_{\mathrm{Y}} t-\tau k_{\mathrm{Y}}
$$
described the adsorption of DC on SBC@ $\beta$-FeOOH in the fixed-bed columns. The $R^{2}$ values were higher than 0.925. The Yoon-Nelson model parameters were shown in Table 2. The times needed for $50 \%$ DC breakthrough from the experiments was in close agreement with the $\tau$ obtained from 
the Yoon-Nelson model. The rate constant $k_{\mathrm{Y}}$ increased and the $50 \%$ breakthrough time $\tau$

322 decreased when both flow rate and DC inlet concentration increased. The values of $\tau$ increased and

323 of $k_{\mathrm{Y}}$ decreased with increasing bed heights. Similar observations were made in sorption studies

324 using granular activated carbon made from waste [51] and chitosan-clay [52].

\section{Table 2}

\subsection{Heterogeneous Fenton oxidation in situ regeneration}

Fig. 5

To exemplify the synergistic effect of adsorption and heterogeneous Fenton-like reaction, the

DC-saturated beds were regenerated by $\mathrm{H}_{2} \mathrm{O}_{2}$. The small variation of the regeneration efficiency of the SBC@ $\beta$-FeOOH beds regenerated with different $\mathrm{H}_{2} \mathrm{O}_{2}$ doses (Fig. 5) . As seen in Fig. 5, the regenerated SBC@ $\beta$-FeOOH bed could attain a breakthrough time that coincided with that of fresh product. degradation efficiency of DC may decrease [53,54]. 
The results demonstrated that flowing relatively low concentrations of aqueous $\mathrm{H}_{2} \mathrm{O}_{2}$ can

344 efficiently restore the sorption capacity of saturated SBC@ $\beta-\mathrm{FeOOH}$ columns. The regeneration performance of saturated SBC@ $\beta$-FeOOH with $5 \% \mathrm{H}_{2} \mathrm{O}_{2}$ in the fixed-bed column for three consecutive loading cycles is also shown in Fig. 5. The regeneration efficiency slightly decreased during the three consecutive cycles, which also coincided with a similar decrease of the adsorption capacity during the first and second absorption cycle. This might result from the stronger affinity of the intermediate products generated during the degradation process of DC. Despite this, the overall results support the idea that SBC@ $\beta$-FeOOH composite integrates the biosorption features of SBC and catalytic properties of $\beta$-FeOOH nanoparticles, implying that the SBC@ $\beta$-FeOOH can be used on multiple absorption cycles.

A schematic of the in-situ regeneration mechanism of the $\mathrm{SBC} @ \beta$-FeOOH composite is presented in Scheme 1. The regeneration processes might be ascribed to the synergistic effect, which works by the cooperation of biosorption merits of SBC and the heterogeneous catalytic reoxidation of $\mathrm{SBC} \equiv \mathrm{Fe}^{2+}$ by $\mathrm{H}_{2} \mathrm{O}_{2}$. Therefore, DC molecules can be oxidized by the combined 
composite were removed completely. In consequence, the saturated adsorption sites on the surface of SBC@ $\beta$-FeOOH composite could be easily regenerated. Compared with other types of adsorbent, such as activated carbon samples with ferric nitrate[46], magnetic porous carbon with maghemite[48] graphene-like layered molybdenum disulfide [58] and montmorillonite[59], the most obvious advantage of $\mathrm{SBC} @ \beta-\mathrm{FeOOH}$ is its regeneration capacity which was structured by heterogeneous Fenton-like oxidation in the treating process of doxycycline.

\section{Conclusion}

A novel and low-cost composite material SBC@ $\beta$-FeOOH, which integrates the biosorption features of SBC and catalytic properties of $\beta-\mathrm{FeOOH}$ nanoparticles, was synthesized in one step via a hydrothermal process. The $\mathrm{SBC} @ \beta-\mathrm{FeOOH}$ proved to be a promising and effective composite material for the removal and the oxidative destruction of DC from aqueous solution performed in a fixed-bed column study. The adsorption of DC on SBC@ $\beta$-FeOOH bed was found to be depended on the influent concentration, flow rate, bed depth and pH. The SBC@ $\beta-\mathrm{FeOOH}$ adsorbent was suitable for the adsorption of DC at acidic, neutral and mildly alkaline $\mathrm{pH}$, with the highest performance observed at acidic $\mathrm{pH}$. The adsorption process was controlled by the ionic speciation of the adsorbate DC and the available binding sites of SBC@ $\beta-\mathrm{FeOOH}$. Under the experimental condition, the column experimental data were analyzed by the Thomas and Yoon-Nelson models. $\mathrm{H}_{2} \mathrm{O}_{2}$-based heterogeneous Fenton oxidation proved to be a viable and efficient process for the in situ regeneration of SBC@ $\beta$-FeOOH saturated beds. The results demonstrate that the sea buckthorn branches are a potential material for the preparation of SBC. Considering the facile method of fabrication of the composite from abundant and low cost agricultural wastes, the superior adsorption performance, the simple and effective way of 
regeneration and the robustness of the adsorbent for consecutive adsorption/regeneration cycles,

389 we conclude that the SBC@ $\beta$-FeOOH composite should be a promising and practical adsorbent

390 for removal and destruction of organic compounds in wastewater. The embedding of $\beta$-FeOOH

391 onto the SBC surface can be extended to the simple fabrication of other $\beta$-FeOOH nanoparticles/agricultural wastes materials.

393

\section{Acknowledgments}

This work was supported by Shaanxi Provincial Natural Science Foundation of China

(No.2015JM2071), National Natural Science Foundation of China (No.21176031) and

397 Fundamental Research Funds for the Central Universities (No. 2014G3292007). 


\section{References}

400

401

402

403

404

405

406

407

408

409

410

[1] L. Ji, W. Chen, S. Zheng, Z. Xu, D. Zhu, Adsorption of sulfonamide antibiotics to multi-walled carbon nanotubes, Langmuir 25 (2009) 11608-11613.

[2] Y. Gao, Y. Li, L. Zhang, H. Huang, J.-J. Hu, S.M. Shah, X.-G. Su, Adsorption and removal of tetracycline antibiotics from aqueous solution by graphene oxide, J. Colloid Interface Sci. 368 (2012) 540-546.

[3] N.K. Amin, Removal of direct blue-106 dye from aqueous solution using new activated carbons developed from pomegranate peel: adsorption equilibriumand kinetics, J. Hazard. Mater. 165 (2009) 52-62.

[4] S. Noreen, H.N. Bhatti, S. Nausheen, S. Sadaf, M. Ashfaq, Batch and fixed bed adsorption study for the removal of Drimarine Black CL-B dye from aqueous solution using a lignocellulosic waste: a cost affective adsorbent, Ind. Crop. Prod. 50 (2013) 568-579.

[5] L.-L. Ding, B. Zou, W. Gao, Q. Liu, Z.-C. Wang, Y.-P. Guo, X.-F. Wang, Y.-H. Liu, Adsorption of Rhodamine-B from aqueous solution using treated rice husk-based activated carbon, Colloids Surf., A 446 (2014) 1-7.

[6] M.C. Ribas, M.A. Adebayo, L.D.T. Prola, E.C. Lima, R. Cataluña, L.A. Feris, M.J. Puchana-Rosero, F.M. Machado, F.A. Pavan, T. Calvete, Comparison of a homemade cocoa shell activated carbon with commercial activated carbon for the removal of reactive violet 5 dye from aqueous solutions, Chem. Eng. J. 248 (2014) 315-326.

[7] R.-M. Gong, Y. Ding, M. Li, C. Yang, H.-J. Liu, Y.-Z. Sun, Utilization of powdered peanut hull as biosorbent for removal of anionic dyes from aqueous solution, Dyes Pigments 64 (2005) 187-192.

[8] W.-F. Liu, J. Zhang, C.-L. Zhang, Y.-F. Wang, Y. Li, Adsorptive removal of Cr (VI) by Fe-modified activated carbon prepared from Trapa natans husk, Chem. Eng. J. 162 (2010) 677-684.

[9] I. Ozdemir, M. Şahin, R. Orhan, M. Erdem, Preparation and characterization of activated carbon from grape 
[10] H. Deng, L. Yang, G.-H. Tao, J.-L. Dai, Preparation and characterization of activated carbon from cotton stalk by microwave assisted chemical activation-application in methylene blue adsorption from aqueous solution, J. Hazard. Mater. 166 (2009) 1514-1521.

[11] D. Savova, E. Apak, E. Ekinci, F. Yardim, N. Petrov, T. Budinova, M. Razvigorova, V. Minkova, Biomass conversion to carbon adsorbents and gas, Biomass and Bioenergy 21 (2001) 133-142.

[12] L. D. Kagliwal, S.C. Patil, A.S. Pol, R. S. Singhal, V. B. Patravale, Separation of bioactives from

[16] M.Gonçalves, M.C. Guerreiro, L.C.A. de Oliveira, C.S. de Castro, A friendly environmental material: Iron

[15] Y. Li, F.-S. Zhang, Catalytic oxidation of Methyl Orange by an amorphous FeOOH catalyst developed from a high iron-containing fly ash, Chem. Eng. J. 158 (2010) 148-153. oxide dispersed over activated carbon from coffee husk for organic pollutants removal, J. Environ. Manage. 127 (2013) 206-211.

[17] R. Song, B. Bai, G.L. Puma, H.-L. Wang, Y.-R. Suo, Biosorption of azo dyes by raspberry-like $\mathrm{Fe}_{3} \mathrm{O}_{4} @ y e a s t$ magnetic microspheres and their efficient regeneration using heterogeneous fenton-like catalytic processes over an up-flow packed reactor, React. Kinet. Mech. Cat. DOI 10.1007/s11144-015-0854-z 
assembled in AAO templates, Mater. Lett. 61 (2007) 1363-1367.

[19] C.-Z. Wei, Z.-D. Nan, Effects of experimental conditions on one-dimensional single-crystal nanostructure of $\beta$-FeOOH, Mater. Chem. Phys. 127 (2011) 220-226.

[20] E.A. Deliyanni, D.N. Bakoyannakis, A.I. Zouboulis, K.A. Matis, L. Nalbandian, Akaganéite-type $\beta$-FeO (OH) nanocrystals: preparation and characterization, Microporous Mesoporous Mater. 42 (2001) 49-57.

[21] T. Miyata, Y. Ishino, T. Hirashima, Catalytic reduction of aromatic nitro compounds with hydrazine hydrate in the presence of Iron (III) oxide hydroxide, Synthesis 11(1978): 834-835.

[22] M. Zhang, Z. Xu, J. Liang, L. Zhou, C. Zhang. Potential application of novel $\mathrm{TiO}_{2} / \beta-\mathrm{FeOOH}$ composites for photocatalytic reduction of $\mathrm{Cr}(\mathrm{VI})$ with an analysis of statistical approach, Int. J. Environ. Sci. Te. DOI 10.1007/s13762-014-0533-z.

[23] C. Zhao, M. Pelaez, X. Duan, H. Deng, K. O’Shea, D. Fatta-Kassinos, D. D. Dionysiou, Role of pH on photolytic and photocatalytic degradation of antibiotic oxytetracycline in aqueous solution under visible/solar light: Kinetics and mechanism studies, Appl. Catal., B- Environ. 134-135 (2013) 83-92.

[24] Y. Gao, Y. Li, L. Zhang, H. Huang, J.-J. Hu, S.M. Shah, X.-G. Su, Adsorption and removal of tetracycline antibiotics from aqueous solution by graphene oxide, J. Colloid Interf. Sci. 368 (2012) 540-546.

[25] M. Ghaemi, G. Absalan, Fast removal and determination of doxycycline in water samples and honey by $\mathrm{Fe}_{3} \mathrm{O}_{4}$ magnetic nanoparticles, J. Iran. Chem. Soc. 12 (2015)1-7.

[26] M. Erşan, E. Bağda, E. Bağda. Investigation of kinetic and thermodynamic characteristics of removal of tetracycline with sponge like, tannin based cryogels, Colloids Surf., B. 104 (2013) 75-82.

[27] S. Zaidi, T. Chaabane, V. Sivasankar, A. Darchen, R. Maachi, T.A.M. Msagati, Electro-coagulation coupled electro-flotation process: Feasible choice in doxycycline removal from pharmaceutical effluents, Arabian J. Chem. DOI 10.1016/j.arabjc.2015.06.009

[28] R. Nacco, E. Aquarone, Preparation of active carbon from yeast, Carbon 16 (1978)31-34 
[29] Z. C. Kadirova, K. Katsumata, T. Isobe, N. Matsushita, A. Nakajima, K. Okada, Adsorption and photodegradation of methylene blue with $\mathrm{Fe}_{2} \mathrm{O}_{3}$-activated carbons under UV illumination in oxalate solution, J. Environ. Chem. Eng. 2 (2014) 2026-2036.

[30] Z.-G. An, J.-J. Zhang, S.-L. Pan, Synthesis and controlled assembly of $\alpha$-FeOOH and $\alpha-\mathrm{Fe}_{2} \mathrm{O}_{3}$ nanobelt arrays on hollow glass spheres, Mater. Res. Bull. 47 (2012) 3976-3982.

[31] H.-J. Song, X.-Q. Zhang, T. Chen, X.-H. Jia, One-pot synthesisofbundle-like $\beta$-FeOOH nanorods and their transformation to porous $\alpha-\mathrm{Fe}_{2} \mathrm{O}_{3}$ microspheres, Ceram. Int. 40 (2014) 15595-15602.

[32] H.-F. Liang, B.-B. Xu, Z.C.Wang, Self-assembled 3D flower-like $\alpha$ - $\mathrm{Fe}_{2} \mathrm{O}_{3}$ microstructures and their superior capability for heavy metal ion removal, Mater. Chem. Phys. 141(2013)727-734.

[33] M. Izquierdo, C. Gabaldón, P. Marzal, F.J. álvarez-Hornos, Modeling of copper fixed-bed biosorption from wastewater by Posidonia oceanica, Bioresource Technol. 101 (2010) 510-517.

[34] E. Oguz, M. Ersoy, Biosorption of cobalt(II) with sunflower biomass from aqueous solutions in a fixed bed column and neural networks modelling, Ecotox. Environ. Safe. 99(2014)54-60.

[35] E. Malkoc, Y. Nuhoglu, Removal of Ni(II) ions from aqueous solutions using waste of tea factory: Adsorption on a fixed-bed column, J. Hazard. Mater. 135 (2006) 328-336.

[36] A.C. Texier, Y. Andr`es, C.F. Brasquet, P.I. Cloirec, Fixed-bed study for lanthanide (La Eu, Yb) ions removal from aqueous solutions by immobilized Pseudomonas aeruginosa: experimental data and modelization, Chemosphere 47 (2002) 333-342.

[37] R. Senthilkumar, K. Vijayaraghavan, M. Thilakavathi, P.V.R. Iyer, M. Velan, Seaweeds for the remediation of wastewaters contaminated with zinc(II) ions, J. Hazard. Mater. 136 (2006) 791-799.

[38] M. Calero, F. Hernáinz, G. Blázquez, G. Tenorio, M.A. Martín-Lara, Study of Cr (III) biosorption in a fixed-bed column, J. Hazard. Mater. 171 (2009) 886-893.

[39] R.-P. Han, Y.-F. Wang, W.-H. Yu, W.-H. Zou, J. Shi, H.-M. Liu, Biosorption of methylene blue from 
[40] P.D. Saha, S. Chakraborty, S. Chowdhury, Batch and continuous (fixed-bed column) biosorption of crystal violet by Artocarpus heterophyllus (jackfruit) leaf powder, Colloid. Surface. B 92 (2012) 262-270.

493

[41] J. Wu, H.-Q. Yu, Biosorption of 2,4-dichlorophenol from aqueous solutions by immobilized Phanerochaete chrysosporium biomass in a fixed-bed column, Chem. Eng. J. 138 (2008) 128-135.

[42] J. Cruz-Olivares, C. Pérez-Alonso, C. Barrera-Díaz, F. Ureña-Nuñez, M.C. Chaparro-Mercado, B. Bilyeu, Modeling of lead (II) biosorption by residue of allspice in a fixed-bed column, Chem. Eng. J. 228 (2013) $21-27$.

[43] S. Chen, Q. Yue, B. Gao, Q. Li, X. Xu, K. Fu, Adsorption of hexavalent chromium from aqueous solution by modified corn stalk: a fixed-bed column study, Bioresource technol. 113 (2012) 114-120.

[44] Z. Aksu, F. G“onen, Biosorption of phenol by immobilized activated sludge in a continuous packed bed: prediction of breakthrough curves, Process Biochem. 39 (2004) 599-613.

[45] R. Jain, M. Mathur, S. Sikarwar, A. Mittal, Removal of the hazardous dyerhodamine B through photocatalytic and adsorption treatments, J. Environ. Manage. 85 (2007) 956-964.

[46] G. Li, D.-S. Zhang, M. Wang, J. Huang, L.-H. Huang, Preparation of activated carbons from Iris tectorum employingferric nitrate as dopant for removal of tetracycline from aqueous solutions, Ecotox. Environ. Safe. 98(2013)273-282.

[47] J. Rivera-Utrilla, C.V. Gómez-Pacheco, M. Sánchez-Polo, J.J. López-Peñalver, R. Ocampo-Pérez, Tetracycline removal from water by adsorption/bioadsorption on activated carbons and sludge-derived adsorbents, J. Environ. Manage. 131 (2013) 16-24.

[48] X.-D. Zhu, Y.-C. Liu, F. Qian, C. Zhou, S.-C. Zhang, J.-M. Chen, Preparation of magnetic porous carbon from waste hydrochar by simultaneous activation and magnetization for tetracycline removal, Bioresource Technol. 154 (2014) 209-214. 
[49] H.C. Thomas, Heterogeneous ion exchange in a flowing system, J. Am. Chem. Soc. 66 (1944) 1664-1666.

[50] Y.H. Yoon, J.H. Nelson, Application of gas adsorption kinetics I. A theoretical model for respirator cartridge service life, Am. Ind. Hyg. Assoc. J. 45 (1984) 509-516.

[51] A.A. Ahmad, B.H. Hameed, Fixed-bed adsorption of reactive azo dye onto granular activated carbon prepared from waste, J. Hazard. Mater. 175 (2010) 298-303.

[52] M. Auta, B.H. Hameed, Chitosan-clay composite as highly effective and low-cost adsorbent for batch and fixed-bed adsorption of methylene blue, Chem. Eng. J. 237 (2014) 352-361.

[53] X.-Y. Li, Y. Huang, C. Li, J.-M. Shen, Y. Deng, Degradation of pCNB by Fenton like process using $\alpha$-FeOOH, Chem. Eng. J. 260 (2015) 28-36.

[54] W. Wang, Y. Liu, T.-L. Li, M.-H. Zhou, Heterogeneous Fenton catalytic degradation of phenol based on controlled release of magnetic nanoparticles, Chem. Eng. J. 242 (2014) 1-9.

[55] L.C.A. Oliveira, M. Goncalves, M.C. Guerreiro, T.C. Ramalho, J.D. Fabris, M.C. Pereira, K. Sapag, A new catalyst material based on niobia/iron oxide composite on the oxidation of organic contaminants in water via heterogeneous Fenton mechanisms, Appl. Catal., A-Gen. 316 (2007) 117-124.

[56] R.C.C. Costa, M.F.F. Lelis, L.C.A. Oliveira, J.D. Fabris, J.D. Ardisson, R.R.V.A. Rios, R.M. Lago, Novel active heterogeneous Fenton system based on $\mathrm{Fe}_{3-\mathrm{x}} \mathrm{M}_{\mathrm{x}} \mathrm{O}_{4}$ (Fe, Co, Mn, Ni): the role of $\mathrm{M}^{2+}$ species on the reactivity towards $\mathrm{H}_{2} \mathrm{O}_{2}$ reactions, J. Hazard. Mater. 129 (2006), 171-178.

[57] L.C.A. Oliveira, M. Goncalves, M.C. Guerreiro, T.C. Ramalho, J.D. Fabris, M.C. Pereira, K. Sapag, A new catalyst material based on niobia/iron oxide composite on the oxidation of organic contaminants in water via heterogeneous Fenton mechanisms, Appl. Catal., A-Gen 316 (2007) 117-124.

[58] Y.-H. Chao, W.-S. Zhu, X.-Y. Wu, F.-F. Hou, S.-H. Xun, P.-W. Wu, H.-Y. Ji, H. Xu, H.-M. Li, Application of graphene-like layered molybdenum disulfide and its excellent adsorption behavior for doxycycline antibiotic, Chem. Eng. J. 243 (2014) 60-67. 
[59] M.E. Parolo, M.C. Savini, J.M. Vallés, M.T. Baschini, M.J. Avena, Tetracycline adsorption on montmorillonite: pH and ionic strength effects, Appl. Clay Sci. 40(2008)179-186. 


\section{Table captions}

Table 1. Parameters in fixed-bed column for DC adsorption by SBC@ $\beta-F e O O H$.

Table 2. Parameters of Thomas and Adams-Bohart models for DC adsorption by SBC@ $\beta-\mathrm{FeOOH}$. 
Table 1.

\begin{tabular}{cccccccccc}
\hline $\begin{array}{c}C_{0} \\
(\mathrm{mg} / \mathrm{L})\end{array}$ & $\begin{array}{c}\mathrm{Z} \\
(\mathrm{cm})\end{array}$ & $\begin{array}{c}Q \\
(\mathrm{~mL} / \mathrm{min})\end{array}$ & $\mathrm{pH}$ & $\begin{array}{c}t_{\text {total }} \\
(\mathrm{min})\end{array}$ & $\begin{array}{c}m_{\text {total }} \\
(\mathrm{mg})\end{array}$ & $\begin{array}{c}q_{\text {total }} \\
(\mathrm{mg})\end{array}$ & $\begin{array}{c}q_{\mathrm{e}} \\
(\mathrm{mg} / \mathrm{g})\end{array}$ & $\begin{array}{c}V_{E f f} \\
(\mathrm{~mL})\end{array}$ & $\begin{array}{c}\text { EBCT } \\
(\mathrm{min})\end{array}$ \\
\hline 22 & 1.1 & 1 & 6 & 80 & 1.760 & 0.593 & 7.409 & 80 & 0.311 \\
27 & 1.1 & 1 & 6 & 64 & 1.728 & 0.459 & 5.734 & 64 & 0.311 \\
32 & 1.1 & 1 & 6 & 48 & 1.536 & 0.385 & 4.816 & 48 & 0.311 \\
27 & 0.7 & 1 & 6 & 44 & 1.188 & 0.264 & 5.286 & 44 & 0.198 \\
27 & 1.1 & 1 & 6 & 64 & 1.728 & 0.459 & 5.734 & 64 & 0.311 \\
27 & 1.5 & 1 & 6 & 88 & 2.376 & 0.744 & 6.767 & 88 & 0.424 \\
27 & 1.1 & 1 & 6 & 64 & 1.728 & 0.459 & 5.734 & 64 & 0.311 \\
27 & 1.1 & 2 & 6 & 31 & 1.674 & 0.456 & 5.703 & 62 & 0.156 \\
27 & 1.1 & 3 & 6 & 18 & 1.458 & 0.448 & 5.597 & 54 & 0.104 \\
27 & 1.1 & 1 & 2 & 108 & 2.916 & 1.072 & 13.403 & 108 & 0.311 \\
27 & 1.1 & 1 & 4 & 84 & 2.268 & 0.753 & 9.408 & 84 & 0.311 \\
27 & 1.1 & 1 & 6 & 64 & 1.728 & 0.459 & 5.734 & 64 & 0.311 \\
27 & 1.1 & 1 & 9 & 52 & 1.404 & 0.302 & 3.773 & 52 & 0.311 \\
27 & 1.1 & 1 & 11 & 32 & 0.864 & 0.203 & 2.533 & 32 & 0.311 \\
\hline
\end{tabular}


Table 2.

\begin{tabular}{cccccccccc}
\hline & & & & \multicolumn{3}{c}{ Thomas model } & \multicolumn{4}{c}{ Yoon \& Nelson model } \\
\cline { 5 - 10 }$C_{0}$ & $\mathrm{Z}$ & $Q$ & $\mathrm{kH}$ & $\begin{array}{c}k_{\mathrm{T}} \times 10^{-3} \\
\mathrm{~mL} / \mathrm{min} \cdot \mathrm{mg}\end{array}$ & $\begin{array}{c}q_{0} \\
\mathrm{mg} / \mathrm{g}\end{array}$ & $R^{2}$ & $\begin{array}{c}K_{\mathrm{Y}} \\
\mathrm{min}^{-1}\end{array}$ & $\begin{array}{c}\tau \\
\mathrm{min}\end{array}$ & $R^{2}$ \\
\hline 22 & 1.1 & 1 & 6 & 2.785 & 7.111 & 0.9435 & 0.061 & 25.97 & 0.9435 \\
27 & 1.1 & 1 & 6 & 2.782 & 4.593 & 0.9404 & 0.075 & 13.63 & 0.9404 \\
32 & 1.1 & 1 & 6 & 3.316 & 3.438 & 0.9837 & 0.106 & 8.60 & 0.9837 \\
27 & 0.7 & 1 & 6 & 4.000 & 2.839 & 0.9675 & 0.108 & 5.26 & 0.9675 \\
27 & 1.1 & 1 & 6 & 2.782 & 4.593 & 0.9404 & 0.075 & 13.63 & 0.9404 \\
27 & 1.5 & 1 & 6 & 2.341 & 6.810 & 0.9253 & 0.063 & 27.83 & 0.9253 \\
27 & 1.1 & 1 & 6 & 2.782 & 4.593 & 0.9404 & 0.075 & 13.63 & 0.9404 \\
27 & 1.1 & 2 & 6 & 6.267 & 4.393 & 0.9359 & 0.169 & 6.51 & 0.9359 \\
27 & 1.1 & 3 & 6 & 12.467 & 4.181 & 0.9620 & 0.337 & 4.13 & 0.9620 \\
27 & 1.1 & 1 & 2 & 2.337 & 15.103 & 0.9142 & 0.063 & 44.75 & 0.9142 \\
27 & 1.1 & 1 & 4 & 2.503 & 9.783 & 0.9163 & 0.068 & 28.98 & 0.9163 \\
27 & 1.1 & 1 & 6 & 2.782 & 4.593 & 0.9404 & 0.075 & 13.63 & 0.9404 \\
27 & 1.1 & 1 & 9 & 3.363 & 1.975 & 0.9275 & 0.091 & 5.85 & 0.9275 \\
27 & 1.1 & 1 & 11 & 6.241 & 1.657 & 0.9846 & 0.169 & 4.91 & 0.9846 \\
\hline
\end{tabular}




\section{Figure captions}

Figure1. XRD pattern of (a) the original SBC powder, (b) parallel $\beta$-FeOOH nanoparticles and (c) SBC@ $\beta-\mathrm{FeOOH}$ samples.

Figure 2. SEM images of (a) overall morphology of original SBC powder, (b) SBC observed under higher magnification, (c) the SBC@ $\beta$-FeOOH products, and (d) an enlarged image of SBC@ß-FeOOH under greater magnification.

Figure 3. Selected zones of SBC@ $\beta$-FeOOH samples (a) and corresponding X-Ray mapping (b) for C, (c) O, and (d) Fe elements.

Figure 4. Effect of (a) initial DC concentration $(\mathrm{Z}=1.1 \mathrm{~cm}, \mathrm{Q}=1.0 \mathrm{~mL} / \mathrm{min}, \mathrm{pH}=6)$, (b) bed depths $\left(C_{0}=27 \mathrm{mg} / \mathrm{L}, \mathrm{Q}=1.0 \mathrm{~mL} / \mathrm{min}, \mathrm{pH}=6\right)$ (c) flow rate $\left(\mathrm{Z}=1.1 \mathrm{~cm}, C_{0}=27 \mathrm{mg} / \mathrm{L}, \mathrm{pH}=6\right)$ and $\mathrm{pH}\left(\mathrm{Z}=1.1 \mathrm{~cm}, Q=1.0 \mathrm{~mL} / \mathrm{min}, C_{0}=27 \mathrm{mg} / \mathrm{L}\right)$ on breakthrough curve.

Figure 5. Schematic of the in-situ regeneration mechanisms (a) and breakthrough time of the regenerated SBC@ $\beta$-FeOOH at various $\mathrm{H}_{2} \mathrm{O}_{2}$ concentration compared with fresh (b) products.

Scheme 1 Formation mechanisms for the SBC@ $\beta-\mathrm{FeOOH}$ composite and their synergetic effect in the removal of DC aqueous solution. 
Figure 1.

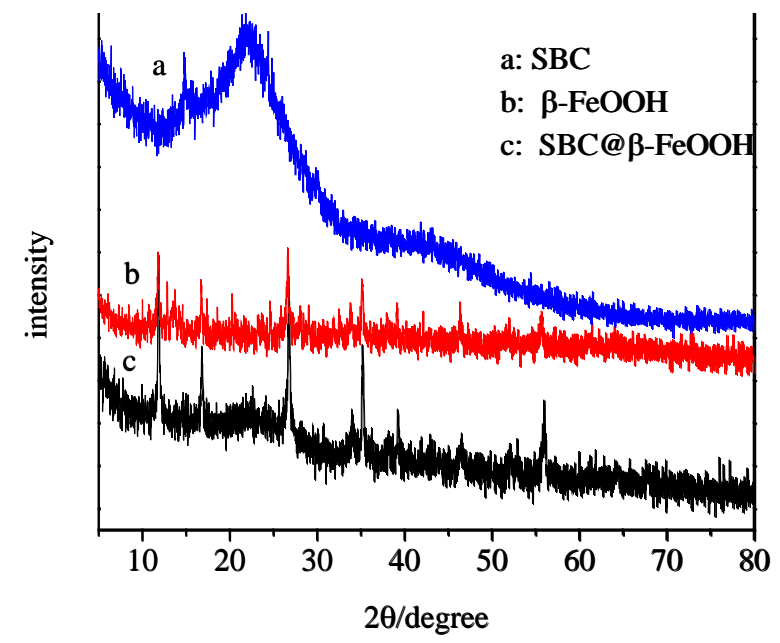


Figure 2.
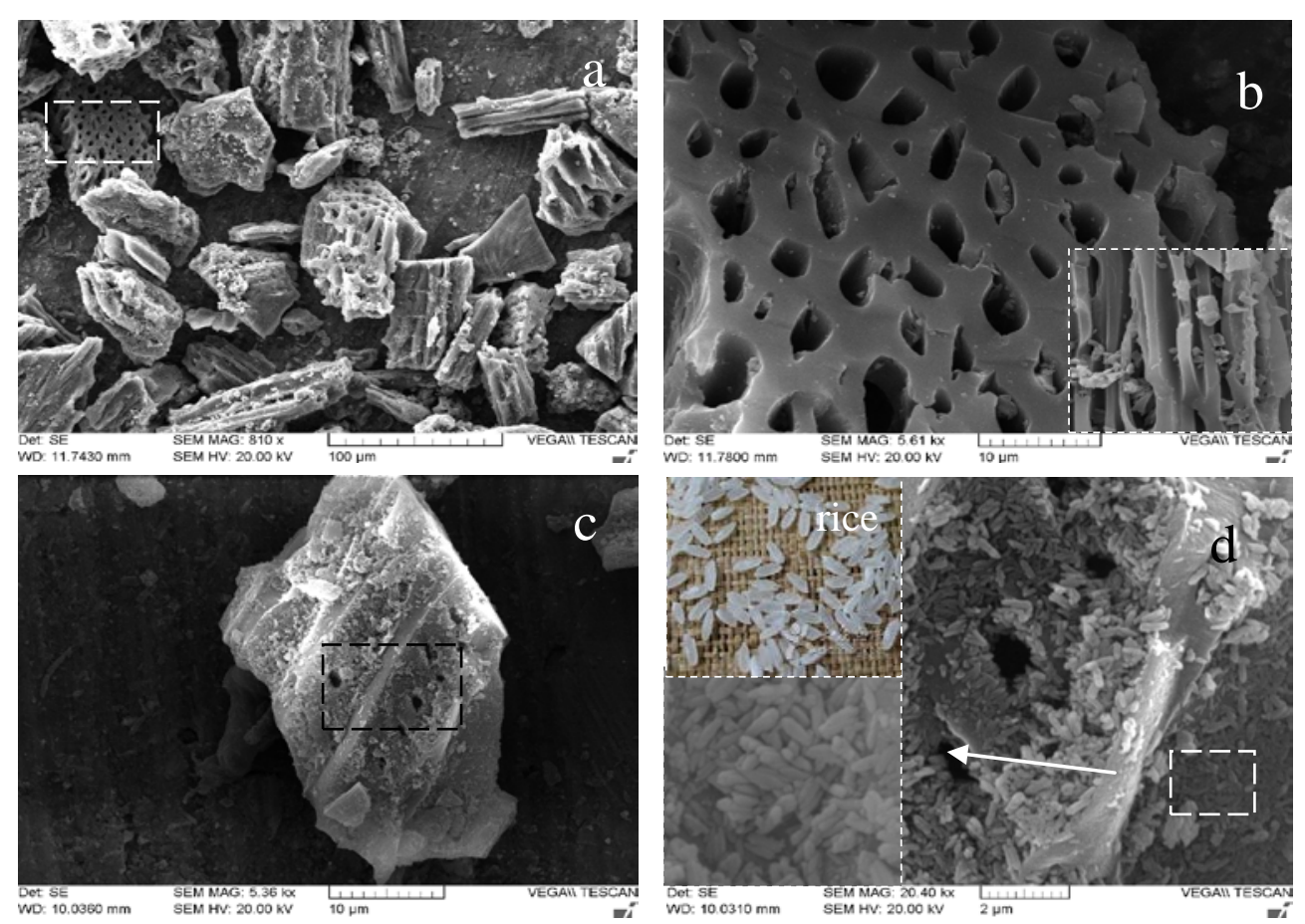
Figure 3.
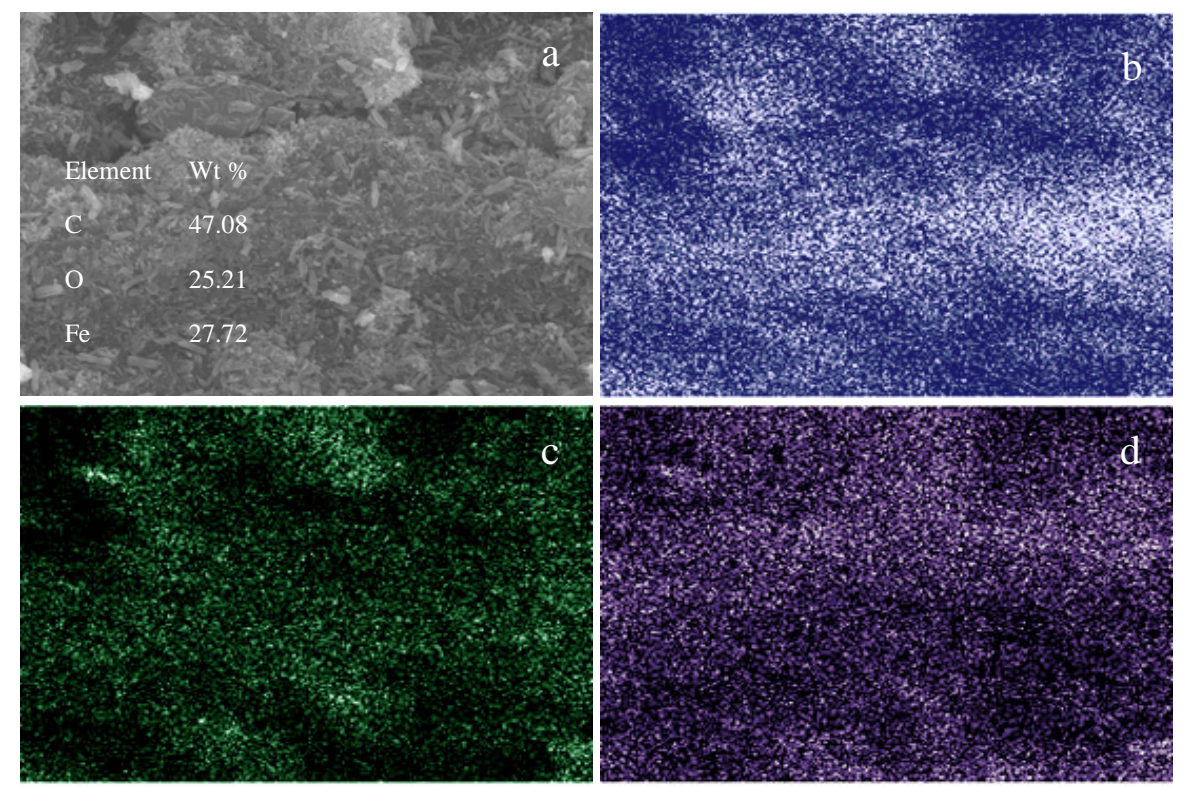
Figure 4.
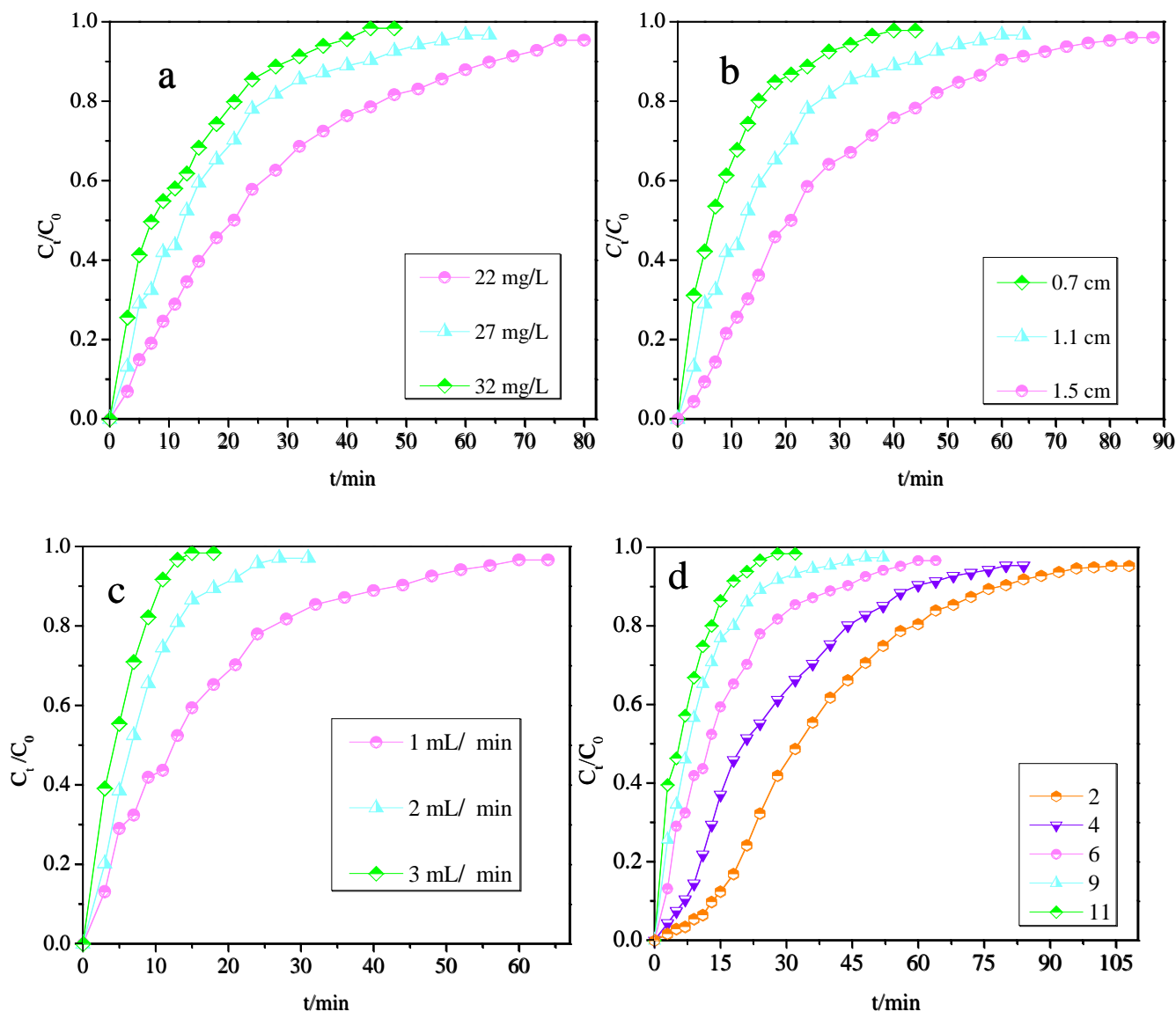
Figure 5.

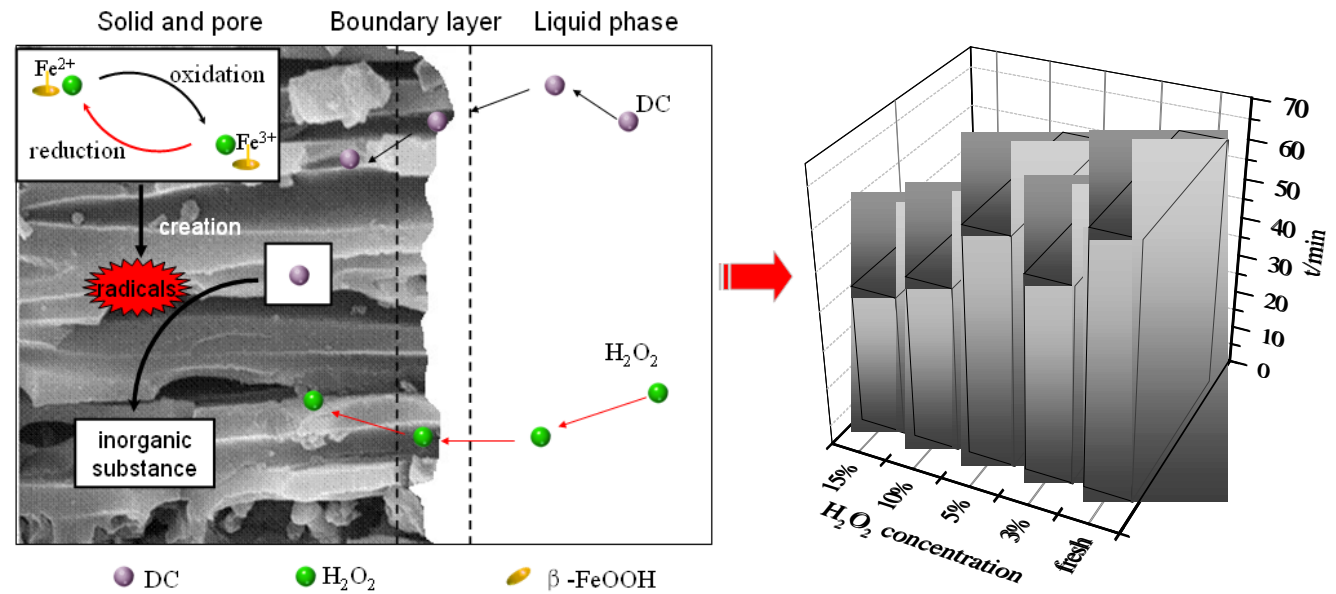




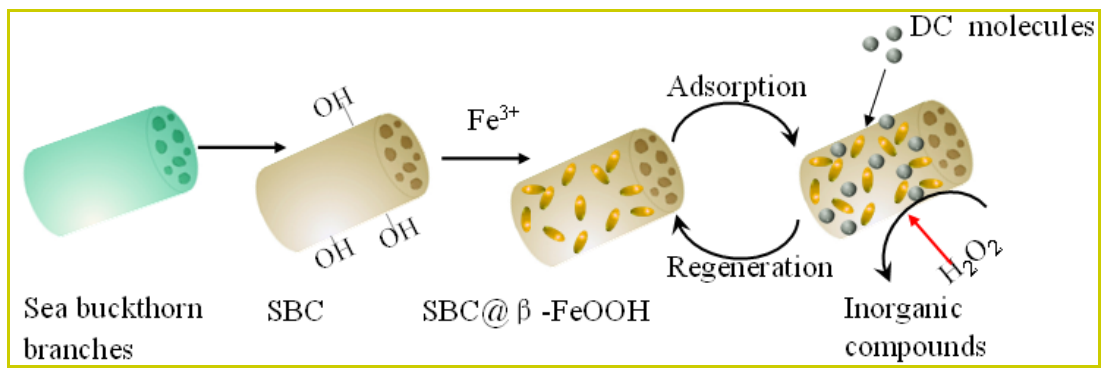

